\title{
INDEKS KETERBACAAN \\ PENGGUNA BUKU KEAGAMAAN KELAS XI \\ DI MADRASAH ALIYAH KAB. GUNUNGKIDUL
}

\section{INDEX ON RELIGIOUS BOOKS USERS READING LEVEL OF $11^{\mathrm{TH}}$ GRADE OF AT MADRASAH ALIYAH OF GUNUNGKIDUL DISTRICT}

\author{
Moch. Lukluil Maknun \\ Peneliti Balai Litbang Agama Semarang \\ Lukluilmaknun84@yahoo.co.id
}

Naskah diterima 10 Oktober 2016, direvisi 15 November 2016, disetujui 20 November 2016

\begin{abstract}
PAI (Islamic Education) Books for Islamic High School of 2013 curriculum have not been evaluated from users' (student and teacher) perspective. This research more focuses on content aspect, however, there are also findings in the form of inputs from users in terms of presentation, language, and graphics. The research uses quantitative approach and Krippendorf content analysis method and CSI (customer satisfaction index), it can be seen that a finding shows that the grading of 11th Grade MA PAl Books users at 5 MA in Gunungkidul District shows that a study course having the lowest average grade of 11th Grade MA PAI (in 1 to 5 scales) is SKI: 3.68 and the highest is Al-Quran and Hadeeth: 4.21, while the other two study courses, namely Religious Behavior (Akidah Akhlak) is 4.20 and Islamic Law (Figh): 3.94. The same result is showed in CSI formula, that the grade /satisfaction criteria (in 1 to 100 scales), study course having the lowest grade is SKI and the highest is Al-Quran and Hadeeth. Details on the users' satisfaction grade are as follows; al-Quran and Hadeeth: 84.13 (very satisfactory), Islamic Culture History: 73.68 (satisfactory), Religious Behavior (Akidah Akhlak): 83.91 (very satisfactory), and Islamic Law (Figh): 78.71 (satisfactory). Even by number, the 11th Grade MA PAI books can be deemed quite good with "satisfactory" and "very satisfactory" satisfaction level, however, there are things that need to be evaluated for improvement. This is indicated by inputs and notes of the users to the content of the books. Among the users' notes on the books in general are; simplification of language and several materials, adjustment of figures, transliteration, references of verses/hadeeths, SKI materials that are too brief, and inclusion of supporting reading source references.
\end{abstract}

Keywords: MA PAI, reading index, CSI, Gunungkidul

\section{Abstrak}

Buku PAI Madrasah Aliyah kurikulum 2013 belum dilakukan evaluasi dari sisi pengguna (siswa dan guru). Penelitian ini lebih memfokuskan pada aspek isi, meskipun demikian terdapat pula temuan berupa masukan dari pengguna dalam hal penyajian, bahasa, dan kegrafikaan. Penelitian ini menggunakan pendekatan kuantitatif dan metode analisis isi Krippendorf serta CSI (customer satisfaction indeks)/analisis kepuasan pelanggan, didapatkan temuan bahwa hasil penilaian para pengguna buku PAI MA kelas XI di 5 MA di Kab. Gunungkidul menunjukkan nilai rata-rata mapel PAI MA kelas XI (dengan skala 1-5) yang terendah adalah mapel SKI: 3.68 dan yang tertinggi adalah mapel Al-Quran dan al-Hadis: 4.21, sedangkan nilai kedua mapel lainnya Akidah Akhlak 4.20 dan Fikih: 3.94. Hasil yang sama ditunjukkan dalam penghitungan dengan rumus CSI, bahwa nilai/ kriteria kepuasan (dengan skala 1-100) yang terendah adalah mapel SKI dan yang tertinggi mapel al-Quran Hadis. Perincian nilai kepuasan pengguna buku sebagai berikut; al-Quran Hadis: 84.13 (sangat puas), Sejarah Kebudayaan Islam: 73.68 (puas), Akidah Akhlak: 83.91 (sangat puas), dan Fikih: 78.71 (puas). Meskipun dalam angka, buku PAI MA kelas XI dapat dinilai sudah baik dengan tingkat nilai kepuasan 'puas' dan 'sangat puas', tetapi terdapat beberapa hal yang perlu dievaluasi sebagai perbaikan. Hal ini tampak dalam hasil temuan masukan dan catatan para pengguna terhadap isi buku. Di antara catatan pengguna terhadap buku secara umum adalah; penyederhanaan bahasa dan beberapa materi, penyesuaian gambar, transliterasi, rujukan ayat/hadis, materi SKI yang terlalu ringkas, dan pencantuman referensi sumber bacaan penunjang.

Kata kunci: PAI MA, indeks keterbacaan, CSI, Gunungkidul 


\section{PENDAHULUAN}

Buku teks pelajaran adalah buku acuan wajib untuk digunakan di sekolah yang memuat materi pembelajaran dalam rangka peningkatan keimanan dan ketakwaan, budi pekerti dan kepribadian, kemampuan penguasaan ilmu pengetahuan dan teknologi, kepekaan dan kemampuan estetis, potensi fisik, dan kesehatan yang disusun berdasarkan standar nasional pendidikan. Buku Teks Pelajaran juga merupakan sumber pembelajaran utama untuk mencapai Kompetensi Dasar dan Kompetensi Inti. ${ }^{1}$

Mengiringi langkah Kementerian Pendidikan Nasional yang memberlakukan kurikulum 2013, Kementerian Agama telah berkomitmen dan siap mengimplementasikan Kurikulum 2013 pada Madrasah berdasarkan KMA Nomor 165 Tahun 2014 pada tahun 2015. Beberapa langkah yang dilakukan Kementerian Agama dalam hal ini adalah menerbitkan Pedoman Teknis Implementasi Kurikulum Madrasah serta menyusun dan menerbitkan buku mata pelajaran Pendidikan Agama Islam bagi Madrasah. Mata pelajaran yang dimaksud adalah al-Quran, Hadis, Fikih, Akidah Akhlak, SKI, Bahasa Arab, Ilmu Kalam, Akhlak, Ilmu Hadis, Ilmu Tafsir, Ushul Fiqh, dan mata pelajaran agama yang lain. Dengan demikian, terkait pemberlakuan kurikulum 2013 mapel PAI di Madrasah yang baru berjalan, dapat dikatakan bahwa buku pegangan mata pelajaran keagamaan di Madrasah masih sangat baru dikenal dan digunakan oleh pengguna.

\footnotetext{
${ }^{1}$ Peraturan Pemerintah Nomor 32 tahun 2013 tentang Standard Nasional Pendidikan, Pasal 1 Ayat 23
}

Alur penerbitan suatu buku pelajaran PAI Madrasah telah melewati proses panjang meliputi pengujian dan koreksi di tingkat pemerintah pusat. Jika buku pelajaran non agama pada jenjang pendidikan dasar dan menengah dinilai kelayakan-pakainya terlebih dahulu oleh Badan Standard Nasional Pendidikan (BSNP) kemudian kelayakan buku teks tersebut ditetapkan oleh Menteri, ${ }^{2}$ buku teks pelajaran Muatan Lokal pada tingkat yang sama dinilai kelayakan-pakainya terlebih dahulu oleh Dinas Pendidikan Provinsi berdasarkan standard nasional pendidikan yang kelayakan pakainya ditetapkan oleh Gubernur, ${ }^{3}$ maka buku pelajaran keagamaan Islam di Madrasah dinilai kelayak-pakainya oleh Direktorat Pendidikan Madrasah Kementerian Agama.

Tujuan penilaian buku teks pelajaran antara lain adalah; menyediakan buku teks pelajaran layak pakai untuk meningkatkan mutu pendidikan nasional; meningkatan mutu sumber daya perbukuan Indonesia; melindungi peserta didik dari buku-buku yang tidak berkualitas; dan meningkatkan minat dan kegemaran membaca. Sedangkan kriteria mutu buku teks antara lain dilihat dari aspek kelayakan isi/materi, penyajian, bahasa, dan kegrafikaan ${ }^{4}$.

Setelah buku pelajaran didistribusikan kepada pengguna, proses evaluasi selanjutnya yang dapat dilakukan demi penyempurnaan buku adalah evaluasi keterbacaanya dalam arti kelayakan dan

${ }^{2}$ Peraturan Menteri Pendidikan Nasional RI Nomor 2 Tahun 2008, Pasal 4 Ayat 1

${ }^{3}$ Peraturan Menteri Pendidikan Nasional Nomor 2 Tahun 2008 pasal 4 Ayat 2

${ }^{4}$ Litbang.kemendikbud.go.id/index.php/15-banpt/116-penilaian-buku-teks-pelajaran 
kesesuaiannya bagi pengguna yaitu siswa dan guru. Dengan banyaknya objek buku pelajaran PAI Madrasah dari tingkat Ibtidaiyah hingga Aliyah, penelitian ini memfokuskan dan membatasi kajian pada buku Mapel PAI MA Peminatan IPA, IPS, dan Bahasa kelas XI sebagai langkah awal untuk melakukan evaluasi. Dengan demikian, tujuan penelitian ini adalah mengukur tingkat keterbacaan buku oleh pengguna terhadap buku pelajaran PAI MA.

\section{Kerangka Konsep dan Tinjauan Pustaka}

\section{Kerangka Konsep}

Mengapa perlu pembatasan pada buku kurikulum 2013 dan hanya buku keagamaan wajib saja dan mengapa menggunakan tema indeks? Hal itu terkait dengan keterbaruan, prioritas keterbacaan di madrasah dan kebutuhan akan suatu parameter yang dapat menentukan bagaimana tingkat keterbacaan buku-buku keagamaan yang dipelajari di sekolah. Untuk memenuhi kebutuhan tersebut, penelitian tentang indeks keterbacaan buku keagamaan di MA akan menghasilkan parameter evaluasi bagi dapat tidaknya buku keagamaan tersebut dipahami siswa sesuai acuan standarnya. Substansinya adalah buku keagamaan MA dilihat sebagai kumpulan materi yang secara teks memiliki potensi untuk dipahami sesuai kategori keterbacaannya, bukan keterbacaan sebagai substansi yang dibatasi pada buku keagamaan MA.

Secara makna etimologis keislaman dengan menggunakan acuan ayat al-Quran, keterbacaan buku keagamaan tersebut tidak sekedar terkait dengan makna membaca sekedarnya yaitu mengikuti kalimat, melihat atau berdasarkan hafalan dan dengan cara mengucapkan atau diam, tetapi terkait pula dengan makna mengumpulkan huruf, kata dan kalimat yang kemudian menjadi kumpulan tema-tema yang satu sama lain dapat membentuk teks atau kumpulan kalimat yang dapat dipahami secara utuh ${ }^{5}$.

Terkait kajian keterbacaan teks keagamaan, dengan demikian tidak hanya melihat teks dengan standard keterbacaan sekedarnya, tetapi memerlukan karakteristik keterbacaan yang jelas. Secara kuantitatif, keterbacaan pada buku teks keagamaan wajib MA sesuai kurikulum 2013 dapat dikaji melalui penentuan indeks keterbacaanya. Indeks tersebut memerlukan parameter keterbacaan berdasarkan konsep keterbacaan teks yang terkait, yaitu adanya relevansi penjelasan isi buku dari segi kohesivitasnya atau konteks microstructure atau representasi isi dengan acuan atau materi intinya 'macrostructure".

Secara istilah, frasa indeks keterbacaan sebenarnya terkait dengan konsep readability indexyang terkait pemahaman membaca dan berintikan pada kualitas kemampuan baca pembaca, bukan tentang kualitas teks, tetapi yang dimaksudkan dalam penelitian ini adalah indeks yang dikaitkan dengan frasa keterbacaan teksnya, sehingga maknanya adalah keterbacaan yang dikaitkan dengan teks saja yaitu buku dan kemudian dikaitkan dengan indeks. Selanjutnya, analisis kualitas keterbacaan buku yang dimaksud dibatasi pada buku PAI MA kurikulum 2013 peminatan IPA, IPS, dan Bahasa yang dari

${ }^{5}$ Umar, A. M. 2008. Mu'jam Al-lughah Al'arabiyyah Almu'ashirah. Diambil kembali dari http://www. shamela.ws. Jil III, h. 1789.

${ }^{6}$ Dijk, T. A. 2006. Discourse, Context and Cognition. Discourse Studies , VIII, 159-177. 
segi materi lebih banyak dibanding buku PAI SMA pada kurikulum yang sama.

Keterbacaan buku dalam konteks analisis isi memerlukan acuan kategori deskripsi kuantitatif yang diukur. Kategori yang digunakan mendeskripsikan indeks keterbacaan buku ini adalah teori inti sari makro struktur buku. ${ }^{7}$ Dalam perspektif teks sebagai bahan kajian makna, materi inti merupakan bagian dari organisasi teks yang diwadahi dalam konteks mikronya. Secara sederhana, buku PAI MA dapat dianggap memenuhi kriteria keterbacaan jika indeks hasil pengkodean isi buku tersebut memenuhi syarat keterbacaan bukunya berdasarkan kategori materi inti.

Pengelompokkan ajaran Islam dalam bentuk mata pelajaran di lingkungan madrasah dimulai dari jenjang Madrasah Ibtidaiyah (MI), Madrasah Tsanawiyah (MTs) dan Madrasah Aliyah (MA) di dalamnya dikhususkan pada peminatan Keagamaan, Matematika dan Ilmu Alam (MIA), Ilmu-Ilmu Sosial (IIS), Ilmu-Ilmu Bahasa dan Budaya (IIBB) serta Madrasah Aliyah Kejuruan (MAK) meliputi: a). Al-Qur'an Hadis, b). Akidah Akhlak, c). Fikih, d). Sejarah Kebudayaan Islam (SKI).

Pada jenjang Madrasah Aliyah (MA) peminatan Ilmu-ilmu Keagamaan dikembangkan kajian khusus mata pelajaran yaitu: a). Tafsir- Ilmu Tafsir, b). Hadis ilmu Hadis, c). Fikih-Ushul Fikih, d). Ilmu Kalam, e). Akhlak. Kemudian dalam upaya mendukung pendalaman kajian ilmu-ilmu keagamaan pada peminatan keagamaan, peserta didik dibekali dengan pelajaran Ibid.

${ }^{7}$ Dijk, T. A. 2006. Discourse, Context and Cognition.
Sejarah Kebudayaan Islam (SKI) serta Bahasa Arab.

\section{Kajian Pustaka}

Beberapa hasil penelusuran pustaka di Google Scholar terkait analisis isi buku PAI MA menunjukkan bahwa telah ada penelitian sebelumnya di antaranya sebagai berikut: Anam ${ }^{8}$ dengan memanfaatkan kajian analisis isi mengkaji nilai-nilai akhlak dalam buku SKI MA, temuannya terdapat pembahasan: 1.) akhlak terhadap Allah SWT ; 2.) akhlak terhadap Rasulullah SAW; 3.) Akhlak terhadap sesama yang meliputi tolong menolong, menjalin persaudaraan, dan musyawarah; 4.) Akhlak kepada Diri sendiri; 5.) Akhlak terhadap keluarga; dan 6.) Akhlak terhadap Negara.

Hampir mirip dengan analisis isi, terdapat contoh kajian dengan memanfaatkan standard penilaian buku dari BSNP, seperti yang dilakukan Muthmainah, ${ }^{9}$ Halim, ${ }^{10}$ dan Nurlaila $^{11}$. Muthmainnah mengkaji isi buku Bahasa Arab MA kelas X mengungkapkan bahwa aspek isi pada buku

${ }^{8}$ Anam, A. S. 2015. Nilai-Nilai Akhlak dalam Mata Pelajaran Sejarah Kebudayaan Islam (Studi Analisis Isi Terhadap Buku Pelajaran SKI Madrasah Aliyah). Yogyakarta: UIN Sunan Kalijaga.

${ }^{9}$ Muthmainnah. 2015. Analisis Perbandingan Kualitas buku teks Pelajaran Bahasa Arab Madrasah Aliyah Kelas X Bermuatan Kurikulum 2013 Terbitan Kemenag, Toha Putra, dan Tiga serangkai. Yogyakarta: UIN Yogyakarta.

${ }^{10} \mathrm{Halim}$, H. A. 2015. Kualitas Buku Ajar Bahasa Arab Kurikulum 2013 (Analisis Standar BSNP Dan Kesilapan Bahasa Buku Ajar Bahasa Arab Terbitan Kemenag Dan Toha Putra). Yogyakarta: UIN Sunan Kalijaga.

${ }^{11}$ Nurlaila, H. 2015. Telaah Bahan Ajar Mahir Bahasa Arab 1 Berbasis Kurikulum 2013 untuk Kelas X Madrasah Aliyah Program Keagamaan Karya Rowi dkk. (Tinjauan dari Segi Kelayakan Materi, Penyajian, Kebahasaan, dan Kegrafikan). Yogyakarta: UIN Sunan Kalijaga. 
teks terbitan Kemenag, Toha Putra, dan Tiga Serangkai masih ditemukan kekurangan dalam hal penyajian latihan dan evaluasi di setiap akhir bab. Selanjutnya, Muthmainnah memberikan persentase urutan kualitas buku terbitan Tiga Serangkai 90,82\%, Toha Putra 90,31\%, dan Kemenag 76,02\%. Halim mengkaji kualitas tiap kategori dari Buku teks Bahasa Arab kurikulum 2013 terbitan Kemenag dan Toha Putra. Nurlaila mengkaji buku Bahasa Arab 1 Kurikulum 2013 karya Rowi dkk, hasilnya mengungkapkan bahwa buku tersebut telah memenuhi beberapa kriteria yang menunjukkan kriteria bahan ajar yang baik, dan sesuai dengan kriteria dalam teori Masnur Muslich.

Adapula kajian buku teks pelajaran PAI MA menggunakan pendekatan jender dan dan politik. Thoriquttyas ${ }^{12}$ dengan perspektif gender mengungkapkan bahwa buku-buku teks pelajaran Fikih, al-Quran Hadis, dan Akidah Akhlak MA kelas X masih didominasi pria dan marjinalisasi wanita dalam persentase penjelasan bukunya. Prasetya ${ }^{13}$ melakukan pengamatan dari sisi politik pada buku Sejarah Kebudayaan Islam kelas X kurikulum 2013 dan hasilnya menyatakan di dalam buku tersebut terdapat pendidikan politik yang meliputi beberapa elemen.

Berdasarkan deskripsi kajian pustaka tentang analisis isi buku Keagamaan MA di atas, dapat diketahui bahwa kajian indeks keterbacaan buku pegangan PAI

${ }^{12}$ Thoriquttyas, T. 2015. Analisis Buku Bahan Ajar Siswa Kelas X Untuk Madrasah Aliyah dalam Perspektif Gender (Studi atas Buku Teks Mata Pelajaran Fikih, Al-Qur'an Hadis dan Akidah Akhlak Kurikulum 2013). Yogyakarta: UIN Sunan Kalijaga.

${ }^{13}$ Prasetya, E. 2015. Pendidikan Politik dalam Buku Siswa Sejarah Kebudayaan Islam Madrasah Aliyah Kelas X Kurikulum 2013. Yogyakarta: UIN Sunan Kalijaga.
MA masih relevan untuk dilakukan jika dikaitkan dengan konteks bahwa di samping dikhususkan pada penelitian evaluasi materi bukuhasil kebijakan penerbitankementarian agama, juga karena perspektifnya adalah pendidikan; sementara dalam kajian analisis isi ini perspektifnya adalah teks pendidikan agama itu sendiri yang dikaji dari segi kualitas teksnya. Artinya, bahwa dalam kajian sebelumnya terdapat kajian teks, parameter perspektifnya adalah pendidikan, baik pendidikan tentang kesetaraan jender, politik, dan lainnya.

\section{METODOLOGI PENELITIAN}

Metode yang digunakan dalam penelitian ini adalah metode analisis isi kuantitatif deskriptif. Secara teknis, metode ini berintikan pada penarikan inferensi kepada konteksnya. Penerapan metode ini dilakukan dengan terlebih dahulu membuat unitisasi data yang relevan dengan tema atau fokus kajian. Selain itu, dalam konteks adanya fokus analisis isi terhadap penarikan inferensi kepada konteksnya, maka perlu dijelaskan bahwa bentuk inferensi penelitian ini adalah (1) inferensi standard, yaitu menyangkut evaluasi, (2) inferensi indeks yang terkait dengan soal kesetujuan atau kesukaan atas kategori tertentu, dan (3) representasi linguistik, yaitu pelibatan unsur bahasa dalam penentuan kategori dan relasi tematiknya ${ }^{14}$.

Unitisasi data terhadap unit fisik berupa Buku KeagamaanWajib/Pegangan Kelas XI MA Kurikulum 2013 di DIY berdasarkan teori van Dijk dilakukan dengan prosedur

${ }^{14}$ Krippendorf, K. 1993. Analisis Isi: Pengantar Teori dan Metodologi. (F. Wajidi, Penerj.) Jakarta: RajaGrafindo Persada. 
sebagai berikut: a) Menetapkan tema sebagai populasi yang diamati dengan unit tema sebagai berikut. 1) Tema inti yang diambil dari judul setiap bab. 2) Tema per sub bab yang merepresentasikan seluruh paragraf atau kalimat, b) Unit tema tersebut diinferensikan kesesuaiannya dengan tema inti sebagai tema acuan untuk menentukan angka (indeks) atau persentase keterbacaan buku, c) Unit tema tersebut kemudian direlasikan dengan tema inti di atas dan diinferensikan menurut konteks indeks keterbacaannya. Artinya, berdasarkan konsep van Dijk, unit analisis kajian ini pembacaan responden terhadap seluruh kalimat atau paragraf per sub bab.

Metode kedua yang digunakan adalah metode CSI (indeks kepuasan pelanggan). Metode ini biasa digunakan sebagai acuan untuk menentukan sasaran-sasaran dan perbaikan di tahun-tahun berikutnya, hal ini diperlukan juga bahwa proses pengukuran kepuasan pelanggan bersifat kontinu. ${ }^{15}$

Metode pengukuran CSI menurut Statford dalam tulisan Buchori, meliputi tahap-tahap berikut: 1) Menghitung Weighting Factor (WF), yaitu mengubah nilai rataan kepentingan menjadi angka persentase dari total rataan tingkat kepentingan seluruh atribut yang diuji, sehingga didapatkan total WF $100 \%$ atau 1. 2) Menghitung Weighting Score (WS), yaitu nilai perkalian antar nilai rataan tingkat kepuasan masing-masing atribut dengan WF masing-masing atribut, 3) Menghitung Weighting Total (WT), yaitu menjumlahkan WS dari semua atribut kualitas jasa, 4)

\footnotetext{
${ }^{15}$ Buchori, Andika. 2006. Analisis Tingkat Kepuasan Pelanggan terhadap Mutu Pelayanan Pada Hotel Holiday Inn Bandung. Bogor: Institut Pertanian Bogor.
}

Menghitung Satisfaction Index, yaitu WT dibagi skala maksimal yang digunakan (dalam penelitian ini skala maksimal adalah 5), kemudian dikali 100\%. Dirumuskan sebagai berikut:

$C S I=\frac{W T}{H S} \times 100 \%$

Keterangan:

CSI : Customer Statisfaction Index

HS : Skor tertinggi

WT : Weighting Total

Kepuasan secara keseluruhan dapat dilihat dari kriteria kepuasan pengguna, dengan kriteria berikut:

Tabel 1

Kriteria Customer Satisfaction Index

\begin{tabular}{|c|c|}
\hline Nilai CSI & Kriteria CSI \\
\hline $0 \%-34 \%$ & Tidak Puas \\
$35 \%-50 \%$ & Kurang Puas \\
$51 \%-65 \%$ & Cukup Puas \\
$66 \%-80 \%$ & Puas \\
$81 \%-100 \%$ & Sangat Puas \\
\hline
\end{tabular}

AdapunMadrasah Aliyah yang dijadikan lokasi penelitian oleh peneliti adalah 5 (lima) MA dari 9 (sembilan) MA di Gunungkidul sebagai berikut (MA lokasi yang ditulis huruf tebal).

Tabel 2.

Data Madrasah Aliyah di Kab. Gunungkidul

\begin{tabular}{|c|c|c|}
\hline No & Man / Kab Gunung Kidul & Alamat \\
\hline 1 & MAN Wonosari & $\begin{array}{l}\text { Jl. Sunan Ampel } 068 \text { Trimulyo } 2 \\
\text { Kepek Wonosari }\end{array}$ \\
\hline 2 & MAS al-I'tisham, Playen & Jl Kiai Legi Siyono Playen \\
\hline 3 & MAS al-Mumtaz Plus & $\mathrm{Jl}$ wonosari Km 25 Pathuk \\
\hline 4 & MAS Darul Qur;an & $\begin{array}{l}\text { Jl Nusantara } 17 \text { Ledok Sari } \\
\text { Kepek Sari Kepek }\end{array}$ \\
\hline 5 & MAS al-Hikmah Karangmojo & Jl Sumberejo, Karangmojo \\
\hline 6 & MAS YAPI Gubuk Rubuh & Gubuk Rubuh Getas Playen \\
\hline
\end{tabular}




\begin{tabular}{lll}
\hline$\frac{7}{8}$ & MAS al-I'anah Playen & MAS Ma'arif Nglipar \\
\hline 9 & MAS Al-Jauhar & Sumberrejo Ngawen Playen \\
\hline
\end{tabular}

Responden ditentukan secara purposif, yaitu para guru bidang studi atau yang ditunjuk oleh Kepala Madrasah jika karena satu dan lain hal, tidak ada guru bidang studinya. Setiap guru tersebut mengisi kuisioner keterbacaan buku menurut bidang studi buku yang dikaji. Beberapa pertimbangan yang perlu diperhatikan untuk perbandingan data responden adalah ada tidaknya sertifikasi guru bidang studi yang bersangkutan dan lamanya mengampu mata pelajaran bidang studinya.

Buku yang dikaji sesuai pembatasan purposif penelitian ini adalah Buku Siswa Akidah Akhlak, al-Quran Hadis, Fikih, dan SKI Kelas XI, Pendekatan Saintifik Kurikulum 2013 terbitan Kementerian Agama Tahun 2015. Sementera itu, Instrumen penelitian yang digunakan berupa lembar-lembar angket yang merupakan form isian bagi responden. Instrumen terdiri dari empat macam sesuai mata pelajaran (alQuran Hadis, SKI, Akidah Akhlak, dan Fikih). Responden diminta untuk menilai keterbacaan buku dalam artian menilai kesesuaian tema/bab dengan sub bab di tiap buku. Penilaian dilakukan dengan memberikan pilihan (centang) dari skala 1-5, kemudian memberikan catatan tambahan atau kritikan pada kolom berikutnya.

Data indeks didapatkan dari rekap hasil isian penilaian keterbacaan buku oleh responden. Adapun catatan tambahan responden merupakan pelengkap data yang digunakan sebagai bahan crosscheckck isian yang kemudian dilanjutkan dengan wawancara untuk menggali lebih jauh dan pada akhir pengumpulan rekap data digunakan sebagai bahan masukan perbaikan buku.

Jumlah item/nomor pertanyaan instrumen per mapel disesuaikan dengan jumlah sub bab mapel yang ada di buku; al-Quran Hadits: 79 pertanyaan; SKI: 31 pertanyaan; Akidah Akhlak: 130 pertanyaan; dan Fikih: 56 pertanyaan.

Pengolahan data dimulai dengan melakukan input isian berupa angka (1-5) ke dalam microsoft excell sesuai mata pelajaran. Hasil rekap kemudian dicari jumlah dan nilai rata-ratanya yang juga dapat digunakan sebagai hasil indeks penilaian responden. Dari proses ini, hasil indeks kuatitatif sudah dapat ditampilkan dalam bentuk tabel ataupun grafik. Tahapan selanjutnya untuk mengetahui besaran kepuasan pengguna buku, dilakukan penghitungan CSI (indeks kepuasan pelanggan) dengan rumus yang disebutkan di awal.

\section{HASIL DAN PEMBAHASAN}

\section{Profil Madrasah Aliyah}

Madrasah Aliyah di Kab. Gunung Kidul untuk kelas XI sudah mempergunakan buku kurikulum 2013, sedangkan pengaplikasian serentak untuk semua kelas baru dimulai pada ajaran 2016/2017. Pada saat penelitian dilaksanakan, yang paling memungkinkan untuk dievaluasi adalah kelas XI, selain karena buku sudah didistribusikan juga sudah digunakan. 


\section{Hasil Penilaian Keterbacaan Buku oleh Responden}

Setelah dilakukan rekap data dan pengolahan instrumen, dengan pengukuran skala 1-5 didapatkan hasil yang dapat dilihat sebagai berikut:

\section{Mata Pelajaran Al-Qur'an Hadis}

Nilai rata-rata keseluruhan mapel AlQur'an Hadis adalah 4.21. Nilai rata-rata tertinggi untuk mapel Alquran Hadis adalah 4.51 oleh MA Al-Ianah, sedangkan nilai ratarata terendahnya adalah 4.00 oleh MA AlJauhar. Grafik rata-rata penilaian per-bab dapat dilihat pada gambar berikut:

Grafik 1.

Hasil penilaian guru mapel Alquran Hadis

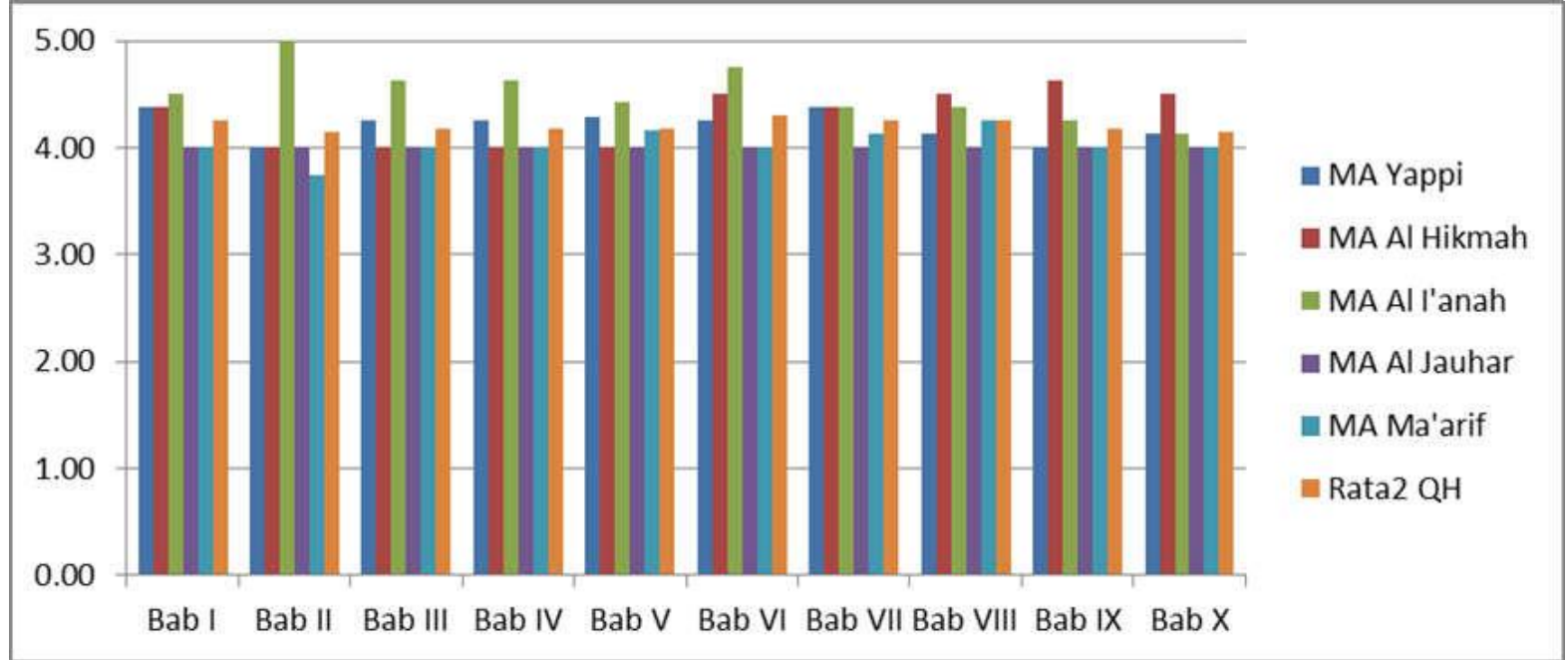

(sumber: olahan data peneliti)

\section{Mata Pelajaran Sejarah Kebudayaan Islam}

Nilai rata-rata keseluruhan mapel Sejarah Kebudayaan Islam adalah 3.68. Nilai rata-rata tertinggi untuk mapel Sejarah
Kebudayaan Islam adalah 4.00 oleh MA AlIanah dan MA Al-Jauhar, sedangkan nilai rata-rata terendahnya adalah 3.00 oleh MA Yappi. Grafik rata-rata penilaian per-bab dapat dilihat pada gambar berikut:

Grafik 2.

Hasil penilaian guru mapel Sejarah Kebudayaan Islam

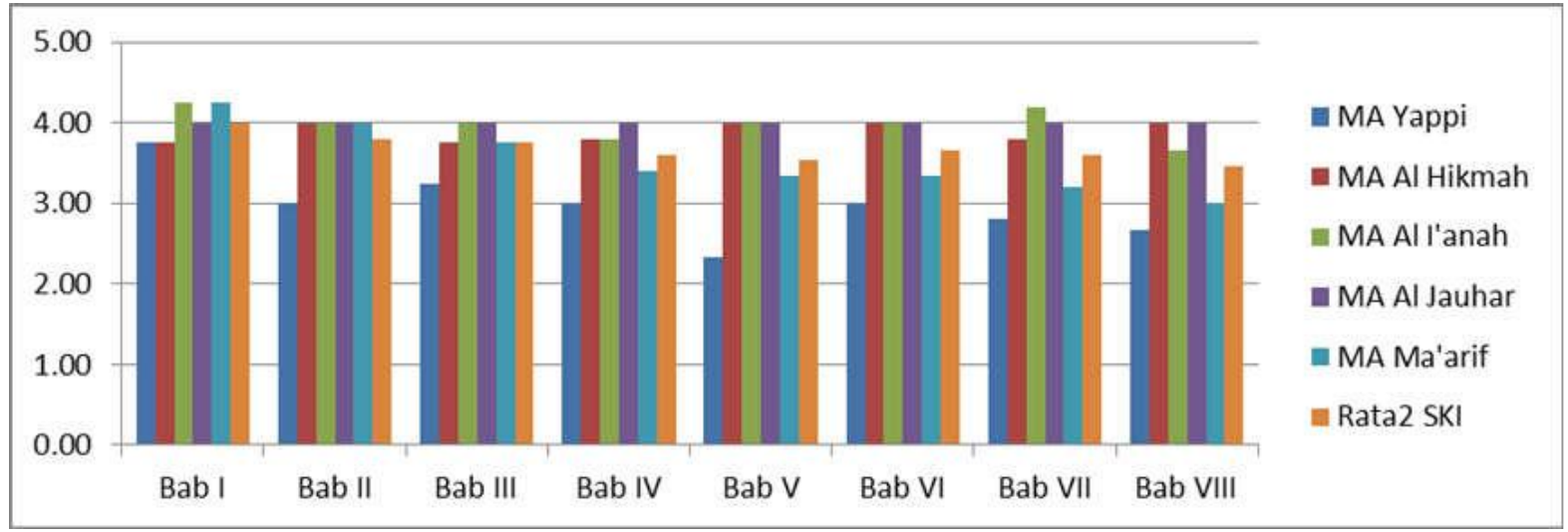

(sumber: olahan data peneliti) 


\section{Mata Pelajaran Akidah Akhlak}

Nilai rata-rata keseluruhan mapel Akidah Akhlak adalah 4.20. Nilai rata-rata tertinggi untuk mapel Akidah Akhlak adalah
4.82 oleh MA Al-Ianah, sedangkan nilai ratarata terendahnya adalah 3.70 oleh MA AlJauhar. Grafik rata-rata penilaian per-bab dapat dilihat pada gambar berikut:

Grafik 3.

Hasil Penilaian Guru Mapel Akidah Akhlak

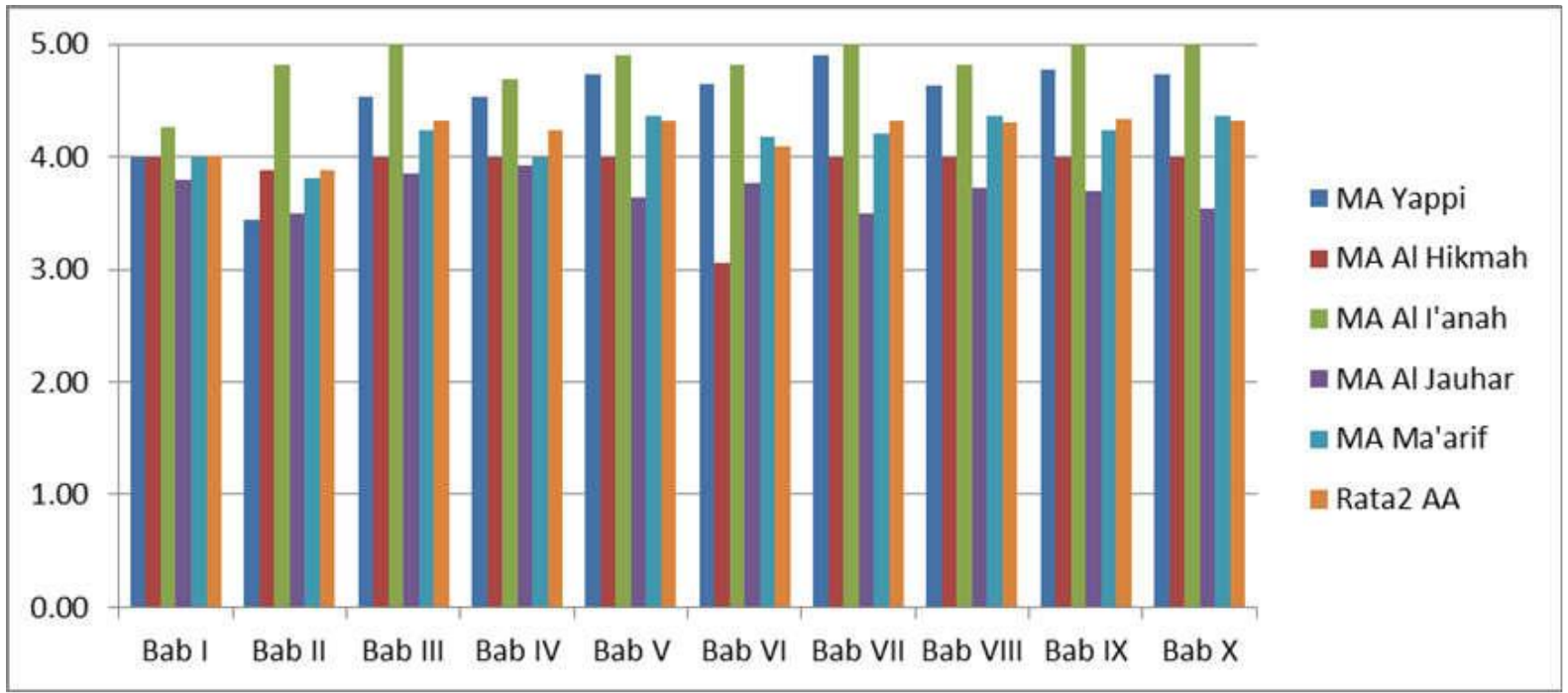

(sumber: olahan data peneliti)

\section{Mata Pelajaran Fikih}

Nilai rata-rata keseluruhan mapel Fikih adalah 3.94. Nilai rata-rata tertinggi untuk mapel Fikih adalah 4.25 oleh MA Al-Ianah, sedangkan nilai rata-rata terendahnya adalah 3.39 oleh MA Yappi. Grafik rata-rata penilaian per-bab dapat dilihat pada gambar berikut:

Grafik 4.

Hasil penilaian guru mapel Fikih

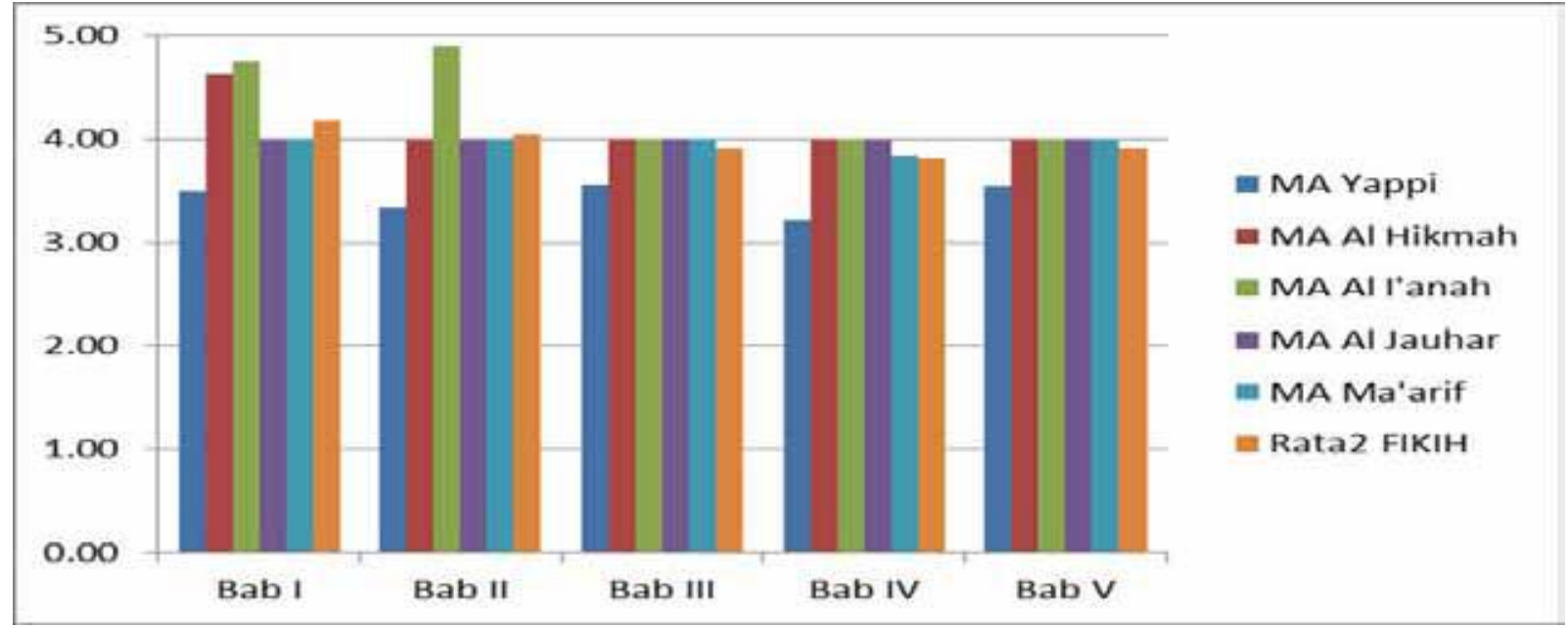

(sumber: olahan data peneliti) 


\section{Hasil Penghitungan CSI (Kepuasan Pengguna)}

Mengukur tingkat kepuasan pengguna buku dapat dilakukan dengan rumus CSI, yang secara garis besar adalah mengetahui posisi nilai buku yang ada sekarang dibandingkan dengan nilai yang diharapkan. Hanya saja, dalam penelitian ini, nilai harapan belum dapat dirumuskan dengan akurat, sehingga nilai harapan dicantumkan nilai maksimal, yaitu nilai 5 dari skala 1-5, atau nilai 100/1 dalam persen.

Nilai CSI Mapel Alquran Hadis adalah 84.13 yang dapat dibaca sebagai kriteria 'sangat puas'. Nilai CSI Mapel Sejarah Kebudayaan Islam adalah 73.68 yang dapat dibaca sebagai kriteria 'puas'. Nilai CSI Mapel Akidah Akhlak adalah 83.91 yang dapat dibaca sebagai kriteria 'sangat puas'. Nilai CSI Mapel Fikih adalah 78.71 yang dapat dibaca sebagai kriteria 'puas'.

Data utama yang digunakan untuk mengukur kepuasan pengguna buku adalah rekap nilai rata-rata per mapel, sebagai contoh, dalam paparan ini disajikan grafik rataan mapel SKI diikuti perhitungan CSInya.

Grafik 5.

Rataan Sejarah Kebudayaan Islam

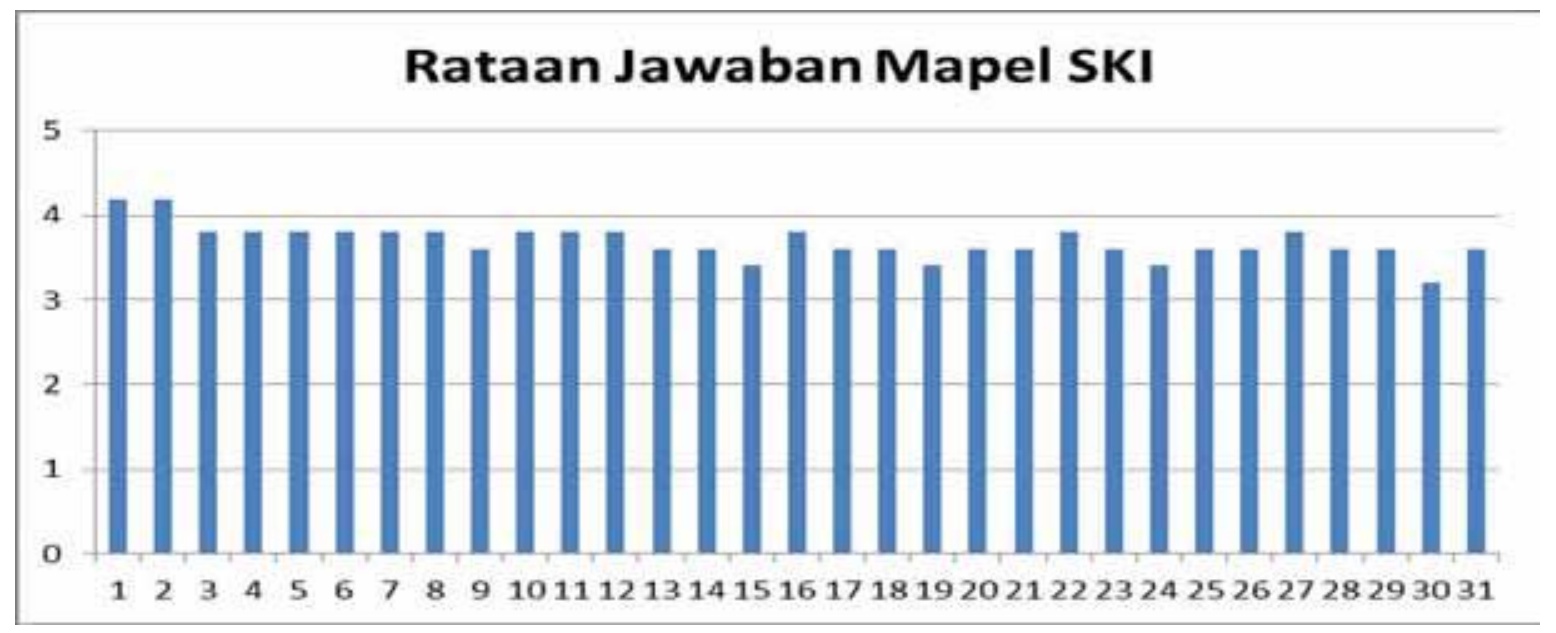

Tabel 3.

CSI Sejarah Kebudayaan Islam

\begin{tabular}{cccccccc}
\hline No & Jumlah jawaban & Rata2 jawaban & jumlah harapan & rata2 harapan & WF & WS & CSI \\
\hline 1 & 21 & 4.2 & 25 & 5 & 3.23 & 13.55 & 73.68 \\
\hline 2 & 21 & 4.2 & 25 & 5 & 3.23 & 13.55 & \\
\hline 3 & 19 & 3.8 & 25 & 5 & 3.23 & 12.26 \\
\hline 4 & 19 & 3.8 & 25 & 5 & 3.23 & 12.26 \\
\hline 5 & 19 & 3.8 & 25 & 5 & 3.23 & 12.26 \\
\hline 6 & 19 & 3.8 & 25 & 5 & 3.23 & 12.26 \\
\hline 7 & 19 & 3.8 & 25 & 5 & 3.23 & 12.26 \\
\hline 8 & 19 & 3.8 & 25 & 5 & 3.23 & 12.26 \\
\hline 9 & 18 & 3.6 & 25 & 5 & 3.23 & 11.61 \\
\hline 10 & 19 & 3.8 & 25 & 5 & 3.23 & 12.26 \\
\hline
\end{tabular}




\begin{tabular}{|c|c|c|c|c|c|c|c|}
\hline No & Jumlah jawaban & Rata2 jawaban & jumlah harapan & rata2 harapan & WF & WS & CSI \\
\hline 11 & 19 & 3.8 & 25 & 5 & 3.23 & 12.26 & \\
\hline 12 & 19 & 3.8 & 25 & 5 & 3.23 & 12.26 & \\
\hline 13 & 18 & 3.6 & 25 & 5 & 3.23 & 11.61 & \\
\hline 14 & 18 & 3.6 & 25 & 5 & 3.23 & 11.61 & \\
\hline 15 & 17 & 3.4 & 25 & 5 & 3.23 & 10.97 & \\
\hline 16 & 19 & 3.8 & 25 & 5 & 3.23 & 12.26 & \\
\hline 17 & 18 & 3.6 & 25 & 5 & 3.23 & 11.61 & \\
\hline 18 & 18 & 3.6 & 25 & 5 & 3.23 & 11.61 & \\
\hline 19 & 17 & 3.4 & 25 & 5 & 3.23 & 10.97 & \\
\hline 20 & 18 & 3.6 & 25 & 5 & 3.23 & 11.61 & \\
\hline 21 & 18 & 3.6 & 25 & 5 & 3.23 & 11.61 & \\
\hline 22 & 19 & 3.8 & 25 & 5 & 3.23 & 12.26 & \\
\hline 23 & 18 & 3.6 & 25 & 5 & 3.23 & 11.61 & \\
\hline 24 & 17 & 3.4 & 25 & 5 & 3.23 & 10.97 & \\
\hline 25 & 18 & 3.6 & 25 & 5 & 3.23 & 11.61 & \\
\hline 26 & 18 & 3.6 & 25 & 5 & 3.23 & 11.61 & \\
\hline 27 & 19 & 3.8 & 25 & 5 & 3.23 & 12.26 & \\
\hline 28 & 18 & 3.6 & 25 & 5 & 3.23 & 11.61 & \\
\hline 29 & 18 & 3.6 & 25 & 5 & 3.23 & 11.61 & \\
\hline 30 & 16 & 3.2 & 25 & 5 & 3.23 & 10.32 & \\
\hline 31 & 18 & 3.6 & 25 & 5 & 3.23 & 11.61 & \\
\hline Total & 571 & 114.2 & 775 & 155 & 100.00 & 368.39 & \\
\hline
\end{tabular}

\section{Komentar dan Catatan Pengguna Buku}

Sebagaimana disampaikan di awal, bahwa dalam penelitian ini dilengkapi dengan catatan dari pengguna buku terkait komentar maupun masukan yang dapat digunakan sebagai bahan evaluasi dan perbaikan terbitan buku berikutnya.

\section{Mata Pelajaran al-Quran Hadis}

Secara garis besar, masukan untuk mapel ini adalah: usulan penyederhanaan bahasa, penyesuaian gambar dengan materi, penambahan contoh deskripsi dari materi, transliterasi Arab-Latin dengan tanda titik kurang familiar, lebih melengkapi rujukan dalam pencantuman redaksi ayat al-Quran dan hadis, serta pemberian tugas yang dikontekskan dengan lingkungan. Rekap masukan dari pengguna dapat dilihat pada tabel berikut.

Tabel 4.

Masukan Mapel al-Quran Hadis

\begin{tabular}{ll}
\hline Bab I & Perlu menggunakan bahasa yang simpel, mudah dipahami, \\
dan tidak terlalu luas.
\end{tabular}




\begin{tabular}{ll}
\hline & Pedoman transliterasi Arab-Indonesia kurang enak dan \\
& nyaman serta sulit diucapkan siswa, berbeda dengan \\
& biasanya (transliterasi model kh dan sejenisnya). Perilaku \\
disampaikan langsung setelah penjelasan ayat. Penulisan & Hadis sebaiknya dilengkapi, sanad lengkap, rawi, kitab dan \\
& nomor Hadis, serta derajat Hadis.
\end{tabular}

\section{Mata Pelajaran Sejarah Kebudayaan Islam}

Secara garis besar, masukan untuk mapel ini adalah: materi mapel SKI cenderung terlalu ringkas, pencantuman tahun masehi di samping tahun hijriah diperlukan, dan pembahasan tokoh-tokoh masa dinasti Abbasiyah dan Umayyah perlu ditambah. Rekap masukan dari pengguna dapat dilihat pada tabel berikut.

Tabel 5.

Masukan mapel SKI

\begin{tabular}{ll}
\hline Bab I Perlu pembahasan mengenai pofil Muawiyah bin Abi Sufyan \\
sebelum masuk Islam, ketika bersama Rasulullah berjuang \\
menegakkan syariat, serta prestasinya bersama Rasulullah.
\end{tabular}

\begin{tabular}{ll}
\hline Bab II & $\begin{array}{l}\text { Buku sebaiknya lebih detil dan terperinci. Buku SKI ini } \\
\text { isinya cenderung bersifat global dan hanya seperti selayang } \\
\text { pandang. }\end{array}$ \\
\hline $\begin{array}{l}\text { Halaman } 15 \text { tahun masehinya perlu ditambahkan agar lebih } \\
\text { jelas. }\end{array}$ \\
\hline Bab III & $\begin{array}{l}\text { Buku SKI K 13 terlalu sederhana, latihan soal kurang, } \\
\text { sehingga perlu ditambah kelengkapan isi dan variasi soal } \\
\text { pertanyaan agar lebih komplit. }\end{array}$ \\
\hline & $\begin{array}{l}\text { Pembahasan mengenai perkembangan ilmu pengetahuan } \\
\text { dan tokoh yang terkenal pada masa Bani Umayah perlu } \\
\text { dilengkapi lagi. }\end{array}$ \\
\hline Bab IV & $\begin{array}{l}\text { Perlu pembahasan cara memahami poin dari kekuasaan Bani } \\
\text { Umayah dan Bani Abbasiyah, bukan hanya dipahami sebagai } \\
\text { perang saudara untuk perebutan kekuasaan. }\end{array}$ \\
\hline Bab V & $\begin{array}{l}\text { Perlu disampaikan hal-hal mendasar tentang peralihan } \\
\text { kekuasaan dari Dinasti Umayyah ke Dinasti Abbasiyah } \\
\text { beserta dampak negatifnya bagi umat Islam. }\end{array}$ \\
\hline Halaman 49, materi perlu diperluas lagi. \\
\hline Bab VI & $\begin{array}{l}\text { Penyampaian materi tentang khilafah-khilafah Bani Umayah } \\
\text { tidak sistematis, sering ada pengulagan materi tentang } \\
\text { khalifah-khalifah. }\end{array}$ \\
\hline Bab VII & $\begin{array}{l}\text { Perlu disampaikan tantangan para ilmuwan Islam dan profil } \\
\text { ilmuwan Islam dinasti Abbasiyah. }\end{array}$ \\
\hline Bab VIII & Cukup \\
\hline
\end{tabular}

\section{Mata Pelajaran Akidah Akhlak}

Secara garis besar, masukan untuk mapel ini adalah: usulan mengubah redaksi 'Tuhan' dengan 'Allah', bahasa perlu disederhanakan dalam materi ilmu kalam dan tasawuf, ada beberapa gambar yang kurang sesuai dengan materi, redaksi hadis hendaknya ditulis dalam tulisan Arab, konsistensi penulisan istilah perlu diteliti kembali, dan hendaknya diberikan arahan referensi yang dapat dituju untuk melengkapi pemahaman materi. Rekap masukan dari pengguna dapat dilihat pada tabel berikut.

Tabel 6.

Masukan mapel Akidah Akhlak

\begin{tabular}{ll}
\hline Bab I & Penggunaan kata "Tuhan" sering digunakan pada kajian \\
& materi ilmu kalam, mengapa tidak menggunakan kata Allah \\
& SWT? Bahasa yang digunakan susah untuk memahamkan \\
& materi ilmu kalam. \\
\hline & Sudah sesuai dan bisa dipertahankan. Namun, ilmu kalam \\
bagi yang jurusan agama sudah ada mapel ilmu kalam, jika \\
pada jurusan agama diberikan dua mapel (Akidah Akhlak dan \\
Ilmu kalam) maka isinya hampir sama.
\end{tabular}


Bab II Gambar sub bab ayo mengamati yang bawah (hal 23) kurang tepat, menunjukkan gambar tentang syirik, sedangkan bab berkaitan dengan aliran ilmu kalam. Hal. 32 pada bahasan Dasar Ajaran ada perbedaan penulisan dengan sebelumnya, hal 32 ditulis artinya dulu, kemudian ayatnya, sedangkan dalam bab sebelumnya selalu konsisten ayat, arti. Penulisan kata Mu'tazilah (hal. 35) ditulis dengan tulisan Muktazilah (di hal. 40). Pada bahasan bab II kebanyakan menggunakan istilah "Tuhan" hal. 40, 41, dll.

No. 18 Sub 23 gambar awal dapat disesuaikan dengan tema.

Bab III Sub bab zina, mencuri, khamr ada pada bahasan di mapel figh XI semester I bab II, alangkah baiknya jika dibedakan kelasnya, atau diubah sub bab menghindari akhlak tercela dengan sub bab lain.

Bab IV Jika hubungannya dengan Hadis, hendaknya ditulis Arab. Hal 100 sub bab menerima jamuan tuan rumah dengan senang hati.

\begin{tabular}{|c|c|}
\hline & $\begin{array}{l}\text { No. } 49 \text { Sub halaman 83, pusar dan lutut adalah termasuk } \\
\text { aurat. }\end{array}$ \\
\hline \multirow[t]{2}{*}{ Bab V } & $\begin{array}{l}\text { Sudah cukup bagus dari tokoh yang disajikan, hanya saja } \\
\text { referensi tambahan dalam bentuk buku sulit ditemukan } \\
\text { (terkhusus Uwais Al Qarni). Soal semester I harusnya urusan } \\
\text { soal disesuaikan dengan urutan materi dari bab I sampai bab } \\
\text { V runtut dan memudahkan siswa dalam mengerjakan (hal } \\
\text { 117). }\end{array}$ \\
\hline & $\begin{array}{l}\text { No. } 62,63 \text { Sub 113, } 114 \text { bisa ditambahkan kisah Lukmanul } \\
\text { Hakim. }\end{array}$ \\
\hline Bab VI & $\begin{array}{l}\text { Materi tasawuf jika diajarkan di Madrasah kelas XI sangat } \\
\text { sulit dipahamkan dan dipahami mengingat tasawuf sangat } \\
\text { susah dipelajari. Kata Allah banyak ditulis dengan kata } \\
\text { "Tuhan" harusnya Allah selalu digunakan karena jelas materi } \\
\text { tentang Islam, contoh hal. } 158 \text { non 4. Bahasa yang digunakan } \\
\text { terlalu puitis. }\end{array}$ \\
\hline \multirow[t]{2}{*}{ Bab VII } & $\begin{array}{l}\text { Untuk bab VII Akhlak pergaulan remaja belum dikuatkan } \\
\text { dengan dalil naqli (Quran dan Hadis) sedangkan materi jelas } \\
\text { berhubungan dengan Akhlak. Hendaknya lebih dikuatkan } \\
\text { lagi agar siswa lebih memahami, tahu hukum, dan bisa } \\
\text { menerapkan dalam kehidupan sehari-hari akhlak terpuji dan } \\
\text { menjauhi akhlak tercela. }\end{array}$ \\
\hline & $\begin{array}{l}\text { No. } 91 \text {. Sub halaman 167. Penggunaan HP Android yang } \\
\text { berlebihan termasuk perbuatan tercela. }\end{array}$ \\
\hline Bab VIII & $\begin{array}{l}\text { Ketika menjelaskan pengertian sebuah istilah berbahasa } \\
\text { Arab, lebih tepat jika ditulis langsung dengan tulisan Arab } \\
\text { bukan latin Indonesia. Contoh hal. 176, 179. }\end{array}$ \\
\hline Bab IX & $\begin{array}{l}\text { Ada ketidakkonsistenan dalam menulis kata "takziyah" } \\
\text { kadang ditulis "takziah" contoh di hal } 195 .\end{array}$ \\
\hline Bab X & $\begin{array}{l}\text { Untuk kisah tauladan sudah cukup bagus. Soal semester } 2 \\
\text { juga masih acak, urutan soal belum sesuai bahasan yang ada. } \\
\text { Contoh, tasawuf adalah bab awal di semester 2, tetapi dalam } \\
\text { soal-soal akhir dikeluarkan lagi, hal. } 216 \text {. }\end{array}$ \\
\hline
\end{tabular}

\section{Mata Pelajaran Fikih}

Secara garis besar, masukan untuk mapel ini adalah: ada gambar yang kurang sesuai dengan materi, beberapa penulisan istilah Arab perlu diteliti, ada beberapa istilah yang lebih baik ditulis dalam redaksi Arab asli, pembahasan materi khitbah perlu ditinjau ulang, dan konsistensi penulisan rujukan ayat dan hadis perlu diteliti kembali. Rekap masukan dari pengguna dapat dilihat pada tabel berikut.

Tabel 7.

Masukan Mapel Fikih

Bab I Pada sub bab mengamati, gambar kurang sesuai. Gambar yang disajikan adalah tentang korupsi (hal 4) sedangkan bab yang dibahas tentang jinayah (pembunuhan, penganiayaan, qishash, diyat, kafarat)

Bab II Tulisan Bughat asal kata بُ harusnya ditulis bughah karena huruf terakhir adalah tak marbutah maka dibaca $h$ jika diwakafkan, hal. 48.

No. 15 Sub halaman 45 Perbedaan dan penjelasan ketiganya kurang jelas, masih dibutuhkan referensi lain.

Bab III Hikmah peradilan sebaiknya diposisikan sebelum rangkuman materi.

Bab tergugat dan sumpah (hal. 67) pada sub d (lafadz sumpah), lafadz "wallahi" agar ditulis dengan Arab agar jelas dalam membaca. Sub bab rangkuman materi judulnya terdapat pada hal 68 (sisa masih banyak) isinya berada di hal 69 tanpa judul.

No. 18 Sub halaman 55 peta konse perlu dibuatkan ke sub peta konsep (pembelajaran lebih efektif)

Gunakan bahasa yang mudah dan simpel.

Bab IV Hal. 73 Gambarnya tidak sesuai. Hal. 79 Definisi khitbah perlu ditinjau ulang. Hal. 80 poin B (Abu Dawud berpendapat boleh melihat seluruh tubuh) perlu ada penjelasan lebih lanjut. Hal. 103 macam-macam iddah harusnya ada nukilan dalil Alquran/Hadis.

Gambar pada kolom mengamati belum sesuai dengan materi terkait nikah (hal 76). Hal 89 sub bab wali dan saksi pada materi wali nikah tertulis "madzhab" di hal. 93 bagian atas tertulis madzhab. Kata-kata yang dipakai mohon untuk lebih diteliti lagi.

No 27 sub bab halaman 73 Tata letak pada bab ada kesaahan judul (Sumber hukum Islam). No. 31 Sub bab halaan 79 Dalam penjelasan mahram banyak kalimat yang membingungkan. No. 32. Sub bab halaman 81 Perlu ada tambahan materi keluarga yang sakinah dalam pernikahan. Undang-undang perkawinan perlu tambahan penjelasan.

Materi diperingkas supaya mudah dipahami dan tidak membuat siswa jenuh membaca.

Bab V Uji kompetensi (latihan) sebaiknya pertanyaannya diperbanyak dan lebih variatif.

Ada ketidakkonsistenan dalam menulis surat dan ayat dalam setap kutipan surat. Contoh hal 121 tentang hukum ilmu mawaris di kutipan ayat ada tulisan 7 : النساء, tidak ada tulisan yang menunjukkan surat dan ayat tetapi di bagian artinya ada. Untuk bab V hukum warisan dalam Islam, mengapa tidak ada sub bab ringkasan materi sperti pada bab-bab sebelumnya yang selalu menyertakan ringkasan materi.

Belum ada contoh soal cara pembagian harta warisan 


\section{PENUTUP}

Buku PAI Madrasah Aliyah belum dilakukan evaluasi dari sisi pengguna (siswa dan guru) sehingga penelitian model evaluasi keterbacaan (kesesuain materi) dapat dilakukan. Aspek yang dinilai dari buku sebagaimana kriteria BSNP ada empat hal, aspek kelayakan isi/materi, penyajian, bahasa, dan kegrafikaan. Penelitian ini lebih memfokuskan pada aspek isi, meskipun demikian dalam penelitian ini pula terdapat masukan dari pengguna yang tidak hanya memberikan catatn terkait isi, tetapi juga aspek-aspek lainnya.

Dari hasil penilaian para pengguna di 5 MA di Kab. Gunungkidul dihasilkan temuan bahwa nilai rata-rata mapel PAI MA kelas XI (dengan skala 1-5) yang terendah adalah mapel SKI: 3.68, sedangkan yang tertinggi adalah mapel Alquran Hadis: 4.21. Hasil rekap keseluruhan dapat dilihat pada tabel berikut.

\begin{tabular}{lccccc} 
Rataan Jawaban Per MA dan per Mapel & & & \\
\hline $\begin{array}{l}\text { Nama Madrasah } \\
\text { Aliyah }\end{array}$ & Alquran H & SKI & $\begin{array}{c}\text { Akidah } \\
\text { A }\end{array}$ & Fikih & $\begin{array}{c}\text { Rataan per } \\
\text { MA }\end{array}$ \\
\hline $\begin{array}{l}\text { MA Yappi Gubuk } \\
\text { Rubuh }\end{array}$ & 4.20 & 3.00 & 4.45 & 3.39 & 3.76 \\
\hline $\begin{array}{l}\text { MA Al Hikmah } \\
\text { Karangmojo }\end{array}$ & 4.29 & 3.87 & 3.86 & 4.09 & 4.03 \\
\hline $\begin{array}{l}\text { MA Al I'anah Playen } \\
4.51\end{array}$ & 4.00 & 4.82 & 4.25 & 4.39 \\
\hline MA Al Jauhar & 4.00 & 4.00 & 3.70 & 4.00 & 3.93 \\
\hline MA Ma'arif & 4.03 & 3.55 & 4.15 & 3.95 & 3.92 \\
\hline Rataan per Mapel & 4.21 & 3.68 & 4.20 & 3.94 & \\
\hline
\end{tabular}

Adapun hasil temuan penghitungan tingkat kepuasan pengguna terhadap buku PAI MA kelas XI di 5 MA di Gunungkidul disebutkan bahwa nilai/kriteria kepuasan (dengan skala 1-100) yang terendah adalah mapel SKI dan yang tertinggi mapel Alquran
Hadis. Perincian nilai kepuasan pengguna buku sebagai berikut; Alquran Hadis: 84.13 (sangat puas), Sejarah Kebudayaan Islam: 73.68 (puas), Akidah Akhlak: 83.91 (sangat puas), dan Fikih: 78.71 (puas).

Meskipun dalam angka, buku PAI MA kelas XI dapat dinilai sudah baik dengan tingkat nilai kepuasan 'puas' dan 'sangat puas', tetapi masih terdapat beberapa hal yang perlu dievaluasi sebagai perbaikan. Hal ini tampak dalam hasil temuan masukan dan catatan para pengguna terhadap isi buku. Di antara catatan pengguna terhadap buku secara umum adalah; a) Perlunya penyederhanaan bahasa pada beberapa materi; b) Ada beberapa gambar yang kurang sesuai dengan materi; c) Transliterasi Arablatin dengan penggunaan tanda titik kurang familiar bagi pengguna; d) Rujukan dalam pencantuman ayat dan hadis perlu lebih diperlengkap; e) Pada beberapa materi perlu ditambahkan pemberian tugas yang dikontekskan dalam kehidupan nyata siswa; f) Materi SKI dinilai terlalu ringkas, perlu ditambah paparan materi dan pengenalan tokoh-tokoh penting masa dinasti Abbasiyah dan Umayyah; g) Tahun masehi perlu disertakan dalam penulisan tahun hijriah untuk memudahkan siswa; h) Materi ilmu kalam dan tasawuf perlu ditinjau kembali untuk diuraikan dengan bahasa yang lebih mudah diterima; i) Penulisan istilah dari Arab perlu ditinjau dan diteliti kembali, ada yang perlu dicantumkan redaksi Arabnya dan konsistensi penulisan transliterasinya; j) Perlu ditambahkan referensi bacaan yang dapat dirujuk oleh pengguna selain dari buk teks untuk memahami materi; k) Pada mata pelajaran fikih, materi nikah perlu ditinjau pada beberapa subnya seperti materi khitbah. 


\section{UCAPAN TERIMA KASIH}

Dalam penelitian ini, penulis perlu menyampaikan terima kasih kepada Puslitbang Kemenag semarang atas kesempatan dan bantuannya terlaksananya penelitian. Juga penulis sampaikan terima kasih kepada kepala sekolah, guru dan para siswa Madrasah Aliyah Gunung Kidul yang telah sudi menjadi bagian dari sumber data dalam penelitian ini.

\section{DAFTAR PUSTAKA}

Anam, A. S. (2015): Nilai-Nilai Akhlak dalam Mata Pelajaran Sejarah Kebudayaan Islam (Studi Analisis Isi Terhadap Buku Pelajaran SKI Madrasah Aliyah). Yogyakarta: UIN Sunan Kalijaga .

Buchori, Andika. (2006): Analisis Tingkat Kepuasan Pelanggan terhadap Mutu Pelayanan Pada Hotel Holiday Inn Bandung. Bogor: Institut Pertanian Bogor.

Dijk, T. A. (2006): Discourse, Context and Cognition. Discourse Studies , VIII, 159177.

Halim, H. A. (2015): Kualitas Buku Ajar Bahasa Arab Kurikulum 2013 (Analisis Standar BSNP Dan Kesilapan Bahasa Buku Ajar Bahasa Arab Terbitan Kemenag Dan Toha Putra). Yogyakarta: UIN Sunan Kalijaga.

Kementerian Agama. (2014): Pedoman Teknis Impelementasi Kurikulum Madrasah,cet-I. Jakarta.

Kementerian Agama. (2015): Akidah Akhlak Untuk Kelas XI. Jakarta.

Kementerian Agama. (2015): Alquran Hadis Untuk Kelas XI. Jakarta.
Kementerian Agama. (2015): Sejarah Kebudayaan Islam Untuk Kelas XI. Jakarta.

Kementerian Agama. (2015): Fikih Untuk Kelas XI. Jakarta.

Kintsch, W., \& Dijk, T. A. (1978): Towards a Model of Text Comprehension and Production. Psychological Review , 85, 363-394.

Krippendorf, K. (1993): Analisis Isi: Pengantar Teori dan Metodologi. (F. Wajidi, Penerj.) Jakarta: RajaGrafindo Persada.

Litbang.kemendikbud.go.id/index.php/15ban-pt/116-penilaian-buku-tekspelajaran

Muthmainnah. (2015): Analisis Perbandingan Kualitas buku teks Pelajaran Bahasa Arab Madrasah Aliyah Kelas X Bermuatan Kurikulum 2013 Terbitan Kemenag, Toha Putra, dan Tiga serangkai. Yogyakarta: UIN Yogyakarta.

Nurlaila, H. (2015): Telaah Bahan Ajar Mahir Bahasa Arab 1 Berbasis Kurikulum 2013 untuk Kelas X Madrasah Aliyah Program Keagamaan Karya Rowi dkk. (Tinjauan dari Segi Kelayakan Materi, Penyajian, Kebahasaan, dan Kegrafikan). Yogyakarta: UIN Sunan Kalijaga.

Prasetya, E. (2015): Pendidikan Politik dalam Buku Siswa Sejarah Kebudayaan Islam Madrasah Aliyah Kelas X Kurikulum 2013. Yogyakarta: UIN Sunan Kalijaga.

Supranto, Johannes. (2006): Pengukuran Tingkat Kepuasan Pelanggan Untuk Menaikkan Pangsa Pasar. Jakarta: PT Asdi Mahasatya.

Supranto, Johannes. (2011): Pengukuran Tingkat Kepuasan Pelanggan Untuk Menaikkan Pangsa Pasar. Jakarta: Rineka Cipta. 
Thoriquttyas, T. (2015): Analisis Buku Bahan Ajar Siswa Kelas X Untuk Madrasah Aliyah dalam Perspektif Gender (Studi atas Buku Teks Mata Pelajaran Fikih, Al-Qur'an Hadis dan Akidah Akhlak Kurikulum 2013). Yogyakarta: UIN Sunan Kalijaga.

Umar, A. M. (2008): Mu'jam Al-lughah Al'arabiyyah Almu'ashirah. III . Diambil kembali dari http://www.shamela.ws 